\title{
An Error Analysis of the Word Class: A Case Study of Chinese College Students
}

\author{
http://dx.doi.org/10.3991/ijet.v10i3.4563 \\ Lixin XIA \\ Guangdong University of Foreign Studies, Guangzhou, China
}

\begin{abstract}
The paper reports a study on the errors in word classes made by Chinese college students in their writings. From the Chinese Learner English Corpus (CLEC), all the errors tagged as [wd2] were collected, and then a general overview of the errors among 4 groups of college students was given. After that, the first 100 errors with the greatest frequency were sorted out from all the errors. They were further classified into 8 categories according to the wrongly used word classes. Based on the actual errors in the CLEC, possible causes of these errors were identified and analyzed. Finally, potential implications for English teaching and learning were discussed and suggestions were put forward.
\end{abstract}

Index terms-English language teaching, Error analysis, Learner Corpora, Word classes

\section{INTRODUCTION}

A word class is "a set of words that display the same formal properties, especially their inflections and distribution."'(Kolln \& Funk, 2008) It is similar to the more traditional term part of speech. However, "When linguists began to look closely at English grammatical structure in the 1940s and 1950s, they encountered so many problems of identification and definition that the term part of speech soon fell out of favour, word class being introduced instead. Word classes are equivalent to parts of speech, but defined according to strict linguistic criteria." (Crystal, 2003) As a result, the term word class is adopted in the present study instead of part of speech.

Lots of studies have been done on word classes, but few of them looked at them from the perspective of second language acquisition. A general retrieval with the key words "errors in word classes" and "errors in parts of speech" in the China National Knowledge Infrastructure (CNKI) only generated 5 results. But all of them are about Chinese word classes for foreign learners. Simple as they seem to be, English as a Foreign Language (EFL) learners experience real difficulty in learning and using them. Consequently, they may make errors in word classes in their compositions. Statistics show that the number of errors in word classes accounts for $4.18 \%$ of the total tagged errors, and rate the eighth in the 63 types of errors in the CLEC, which is even greater than that of errors in collocations (Gui Shichun, 2005:13). Just as Ellis (2008:18) notes that learners apparently follow a very similar pattern of development, Chinese EFL learners might make common errors in the word class. Therefore, the present study aims to find out these errors based on the CLEC in an attempt to help shed light on the main problems and difficulties they encounter in the acquisition of the word class.

\section{AN OVERVIEW OF WORD Class ERRORS}

Built by Gui Shichun in 2002, the CLEC was a tagged learner corpus with about 1 million tokens (Gui Shichun, Yang Huizhong 2002:3). It was made up of written texts by Chinese English learners of 5 groups: high school students (st2), lower grade college students (non-English major) (st3), higher grade college students (non-English major) (st4), lower grade college students (English major) (st5) and higher grade college students (English major) (st6). They were all EFL learners in China, but they were at different learning stages. In other words, they were at different levels of proficiency in English. The students from the group st 2 were beginners. The students from the group st 3 and st 4 were intermediate learners. And the students from the group st5 were advanced learners. However, the amount of material from each group was equal in the CLEC, i.e. about 200,000 tokens for each group. As this study focuses on the errors made by college students, only the material from st 3 , st 4 , st5 and st 6 were collected.

Errors in word classes are tagged as [wd2] in the CLEC. Through data retrieval, we got 2,596 [wd2] tags in the corpus, and the number of errors made by each group of st3, st4, st5 and st6 is 1,081, 937, 269 and 309 respectively which accounts for $42 \%, 36 \%, 10 \%$ and $12 \%$ as shown in Fig. 1.

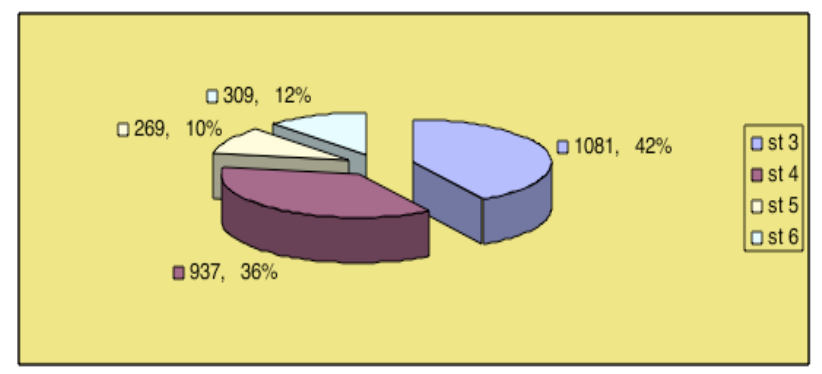

Figure 1. Rate of the errors in word classes for each of the four groups

From Fig. 1, we can see that the error rate in word classes relates closely to learners' English proficiency. NonEnglish majors (st3 and st4) committed much more errors than English majors (st5 and st6) did (78\%:22\%); and the lower grade college students (st3) made more errors than higher grade college students (st4) $(42 \%: 36 \%)$. The less advanced learners (st3) committed more errors compared with the more advanced learners (st4, st5 and st6). However, word classes pose problems for each group of students.

In all the errors in word classes, 688 of them appeared only once which makes up $26.5 \%$ of all. 180 of them appeared twice, 73 of them three times and 48 of them four 
times. This shows that not all the Chinese learners make the same form of errors in the word class.

However, the greatest frequency was 81 for the word economic. Next came the word increasing (78), social (66), success (47), haste (38), and developing (37). So learners made these errors repeatedly. This deserves our attention.

\section{ClassificATION OF THE ERRORS}

In order to have a clearer picture of the errors, we sorted out the first 100 errors with the greatest frequency from all the errors. They are listed in TABLE I. The frequency ranges from 4 to 81 . It is interesting to find out that the number 11 is a critical point. The number above it has a frequency of more than 20. The frequency decreases markedly for the first 10 errors, but gradually for the rest of them.

We further classified these 100 errors according to the misused word class of these words. In Ex. 1, the adjective broad was wrongly used as a verb in the sentence; and the right word should be broaden. This kind of error will be classified into the group of $a d j-v$, meaning an adjective is mistakenly used as a verb. Tao Xiaoyue (2006:31) noticed the same phenomenon in which Chinese learners erroneously used an adjective as a verb, functioning as a predicate in the sentence like Ex. 1. The classification is shown in TABLE II.

\section{Ex. 1 studying abroad helps to broad [wd2,2-2]our mind and train our character.}

English word classes are comprised of open classes (nouns, adjectives, verbs, and adverbs) and closed classes (pronouns, prepositions, conjunctions, articles, interjections, and others). From TABLE II, we can see that all the errors in word classes are open classes with 44 misused adjectives, 23 nouns, 19 verbs and 9 adverbs. But it doesn't mean closed classes will not be misused by Chinese learners as we only sorted out the first 100 word forms with the greatest frequency.

For adjectives, Chinese learners may misuse them as nouns, adverbs or verbs. Below are the examples extracted from the CLEC with the errors highlighted by boldface.

$$
\begin{gathered}
\text { Ex. } 2 \text { so the students must do as good [wd2,-] as } \\
\text { they can to reduce his } \\
\text { Ex. } 3 \text { en be prone to work in the social [wd2,1-1] } \\
\text { and the women stay at } \\
\text { Ex. } 4 \text { Because it may make people lost [wd2,-] their } \\
\text { lives. Of course we all }
\end{gathered}
$$

Ex. 2 is a case of $a d j-a d v$, i.e. the adjective was misused as an adverb. It is very common in Chinese learners' compositions, especially in the context of as...as where the adverb was separated from the verb it modified. In Ex. 3 , the noun society should be used instead of the adjective social. It belongs to the type of adj- $n$. It is the most common type of errors in the CLEC. Ex. 4 is a less common type of error where the adjective was misused as a verb, i.e. $a d j-v$.

Nouns may be wrongly used as adjectives or verbs. Here are the examples from the CLEC:

$$
\begin{aligned}
& \text { Ex. } 5 \text { to get it too fast, you will failure [wd2,1-]. } \\
& \text { We said [vp6,-s], haste } \\
& \text { Ex. } 6 \text { fresh water is relatively shortage [wd2,2-] } \\
& \text { Nowadays, the shortage }
\end{aligned}
$$

In Ex. 5, the learner misused the word failure as a verb. He or she intended to say that we sometimes need to slow down, or we will fail. It is a type of $n-v$ error. Ex. 6 is a type of $n$-adj error where a noun was incorrectly used as an adjective. This is an uncommon case because the noun shortage is much more difficult than the adjective short.

For verbs, learners may misuse them as nouns or adjectives. The $v$ - $n$ type of errors is more common than the $v$ adj type. Below are the examples from the CLEC.

$$
\begin{gathered}
\text { Ex. } 7 \text { it [wd5,1-] will lead to succeed [wd2,-] easi- } \\
\text { ly. But another people } \\
\text { Ex. } 8 \text { the women's power is limit [wd2,1-] in con- } \\
\text { trast with the men's pow }
\end{gathered}
$$

In Ex. 7, the verb succeed was used where a noun success should be used instead. In Ex. 8, the learner confused the adjective limited with the verb limit.

The last type of error is $a d v$-adj. In that case, an adverb is inappropriately used as an adjective.

$$
\begin{gathered}
\text { Ex. } 9 \text { newspaper is the most simply [wd2,2-] and } \\
\text { efficient way. We can }
\end{gathered}
$$

In Ex. 9, the learner used the adverb simply where the adjective simple should be used.

Careful readers might have found that the last 5 words listed in TABLE II had not been assigned an error type. These five words are firstly, they, means, living and economics. Below are the sentences taken from the CLEC:

\section{Ex. 10 If I were you, I would make a plan firstly [wd2,-]. Then I would finish it step \\ Ex. 11 o [wd5, $s$-] eating! They also build they [wd2,3-1] industries, developing [vp 4 \\ Ex. 12 ery and dehumanization, then, the means [wd2, 1-] of euthanasia should be \\ Ex. 13 e is more distinct. Because the economics [wd2,1-3] of developing countries is Ex. 1430 years, people can live a good living [wd2,2-] and have a good medical [w}

In Ex. 10, the learner used firstly instead of first, both of which belonged to the same word class. It is the same for the other four words. Therefore, although they were tagged as errors in word classes in the CLEC, they were not rated as an error in the word class in the present study.

To sum up, we have 8 types of errors in word classes. They are adj-adv, adj-n, adj-v, n-v, n-adj, v-n, v-adj, and $a d v$-adj. Among the 8 types of errors, the type $a d j-n$ is the most common one. Besides, adjectives can be misused as all the other members of open classes. Therefore, adjectives are most likely to be wrongly used by Chinese learners. Next are nouns which can be misused as verbs or adjectives. And verbs can also be wrongly used as nouns or adjectives. Finally are adverbs which can be improperly used as adjectives.

\section{Possible Causes Of The ERrors}

As stated above, Chinese learners made more errors in word classes than those in collocations. They are very common in their writings. Corder $(1981: 19)$ notes that one of the principal reasons for studying the learner's language is precisely to discover why it is as it is, that is, to explain it and ultimately say something about the learning process. Therefore, possible causes of the errors are discussed below. 


\section{A. Difference in the use of an adjective between English} and Chinese

In general, an adjective is a modifier used to modify a noun or noun phrase. However, an adjective can also be used as a noun or noun phrase in a sentence both in English and Chinese. The difference lies in that in Chinese an adjective can be used as a noun directly, but in English the definite article or other determiners must be added before it. For example, in Chinese one can say "chengshi (honest) shi (is) yizhong (a) meide (virture)" in which chengshi is an adjective meaning honest. The correct English version of this sentence is "Honesty is a virtue". While in English one can say "the old and the young marched together" in which the definite article is used before the adjective to refer to a particular group of people who are old or young.

Another difference in the use of an adjective between English and Chinese is that an adjective in Chinese can be used to perform the function of a disjunct. However, in English, a disjunct is an adverb or adverbial that is loosely connected to a sentence and conveys the speaker's or writer's comment on its content, truth, or manner. For example, one can say "xianran (obvious), daan (answer) shi (is) kendingde (positive)." in Chinese whose English version is "obviously, the answer is positive". Below are the examples extracted from the CLEC.

Ex. 15 Obvious [wd2,s-] these people compare television with opium.

Ex. 16 General [wd2,-4] speaking, men are taking a leading role in th

Ex. 17 General [wd2,-1] speaking, after the study in $[w d 3,-2]$ the sch

Ex. 18 General [wd2, -1] speaking whether would I change my job depen

Ex. 19 But I think, general [wd2, 1-] speaking, if you are good enough, there will

Ex. 20 But general [wd2, 1-] speaking, the more education you receive, th

In these sentences, adjectives were mistakenly used to perform the function of a disjunct where adverbs should be used.

\section{B. Difference in the conversion of the word class between English and Chinese}

English and Chinese differ from each other in the conversion of the word class. In English, it is often accomplished by inflection. For example, the noun form of the verb punish is punishment. However, in Chinese, a same word form can be used both as a noun or a verb without any change of the word form. For example, in the sentence "ta (he/she) shoudele (be) chengfa (punish)", cheng$f a$ is a verb. Its English version is "he/she was punished". In the phrase "dui (for) fubai (corruption) guanyuan (official) de (of) yanli (tough) chengfa (punishment)", chengfa is a noun. Its English version is "tough punishments for officials convicted of corruption". Below are the examples extracted from the CLEC.

Ex. 21 he also can think about to choice [wd2,1-] his futur's [fm 1,-] creer [fm1,-] .

Ex. 22 There are many ways for us to choice [wd2,1-], such as the people, the 7
Ex. 23 If I am given a chance to choice [wd2,-] I would prefer the [np9,-] teaching.

Ex. 24 s realities. [sn $8, s-]$ I don't have much chance of choice [wd2,1-] work.

Ex. 25 and this makes it capable [wd3,s-] that we choice [wd2,s-] our jobs.

Ex. 26 People can choice [wd2,s-] one at [wd3,-3] their different characters.

Ex. 27 One can choice [wd2,-2] any job from hundreds of jobs. But someone li

Ex. 28 Then I will choice [wd2,-s] a fivourist [fm1,-] job to do for a long time

Ex. 29 believe yourself, and choice [wd2,-s] the mode of life you want.

Ex. 30 then choice [wd2,-2] a constant job which I loved [vp6,-s] very mu

Ex. 31 In my opions [fm 1,-], a person should choice [wd2,-] a job in terms of

Ex. 32 There are many kinds of sports that we can choice [wd2,-]. In my

Ex. 33 achuting and sky-ballet may be the sports we can choice [wd2,-] .

Ex. 34 which means not only the employees can choice [wd2, 1-] our graduate

Ex. 35 but also our graduate [np6, s-] can choice [wd2, 1-] employees.

In Chinese, xuanze can be used as a noun and a verb. It has two equivalents in English: the noun form choice and the verb form choose. Ex. 21 to Ex. 35 are all the cases of misusing the noun choice as the verb choose.

\section{Difference in the use of a verb between English and Chinese}

In Chinese, a verb can be followed by another verb directly without any conjugation of the latter one. For example, it is grammatical to say "wo (I) feichang (very much) xihuan (like) da (play) lanqiu (basketball)". But in English, we are required to change the second verb play into playing or to play. So the correct English version of the above Chinese sentence is "I like playing/to play basketball very much". Besides, in an English sentence, the verb after a preposition must be in the form of a gerund. Below are the examples taken from the CLEC.

Ex. 36 I want succeed [wd2,-] as all the people

Ex. 37 Thirdly, every one has right to choose live [wd2, 1-2] or die, the traditional

Ex. 38 the progress of economy in the develop [wd2,1-1] countries led [vp1,-4] the life

Ex. 39 If you want to haste [wd2,2-], the chance of succeed [wd2,1-] will go

Ex. 40 we must be very careful, in case of fail [wd2,]

In Ex. 36 and Ex. 37, the verb succeed and live should be in the form of an infinitive. It is ungrammatical to put a second verb directly after the predicate verb. In Ex. 38, the verb develop should be in the form of "developing". Ex. 39 and Ex. 40 are both the case of using a verb directly after a preposition where a gerund is grammatically required. 


\section{Similar spellings of the words}

Some English words are spelt in a similar way, which will be difficult for learners to distinguish them, especially for less advanced learners. As a result, they may confuse one word with another in their writings. If the wrongly used words belong to different word classes, then they were classified as errors in word classes in the CLEC.

Ex. 41 Maybe in American people opposite [wd2, 1] euthanasia not because of

Ex. 42 tell the children that there is a fairly [wd2, 1J lady dressed in white

Ex. 43 hearing his hard deep breathe [wd2, 1-] sound, I was suffering with him.

Ex. 44 but just give me some advise [wd2, 1-] I have right to keep my friend as my

Ex. 45 writing to you to make a complain [wd2, 1-] on the noise that disturbs me.

Ex. 46 Because we are in hasty [wd2, 1-], we have a press [wd3, 2-], we can't do

In Ex. 41, the learner wrongly used opposite as oppose. These two words are spelt similarly, but they don't relate to each other in their meaning. The same is true of Ex. 42 in which the mistakenly used word fairly has nothing to do with the word fairy in their meaning. However, from Ex. 43 to Ex. 46, the learners misused the words which are same in their meaning. Actually, they belong to the same word family, for instance breath and breathe, advice and advise.

\section{E. Transfer of training}

Although the word class is the basic element of English grammar, it is overlooked by English teachers in their teaching. They take it for granted that English learners will naturally acquire word classes without any particular efforts. Other grammatical knowledge is much more important than the word class. So they don't give their students enough training in the word class. Moreover, the teaching material also overlooks the word class. They don't provide learners with sufficient exercises in word classes. Let's take the Chinese-English dictionary as an example. This kind of dictionary is mainly used for production. However, the English equivalents in these dictionaries are not provided with a word class label. As a result, the learner may misuse them in word classes.

In sum, Chinese learners may commit errors in word classes for various reasons. According to Selinker,"In every instance of the multiple effects principle, language transfer will be involved." (1992:263). From what is stated in section 4 , we can see that interlingual transfer might account for most of the errors. As there are substantial differences between Chinese and English in regard to the word class, Chinese learners may inappropriately apply their mother tongue rules and knowledge to their English learning. Consequently, they make errors in word classes. Apart from mother tongue interference, intralingual transfer may also cause Chinese learners to make errors in word classes. When they learn a foreign language, they tend to apply what they have learned to a new item. If they overgeneralize certain target language rules, errors arise. At last, according to Selinker and Lakshmanan's (1992) Multiple Effects Principle, when two or more factors work in tandem, Chinese learners are more likely to make errors in the word class.

\section{CONCLUSIONS}

From what is stated above, we may reach the following conclusions. First of all, Chinese learners tend to commit errors in the word class systematically. Generally speaking, less advanced learners make more errors than more advanced learners do. But all the four groups of college students commit errors in word classes. So these errors are not sporadic but repeated in a systematic way.

Secondly, errors in word classes are very common among Chinese English learners. Most of the errors are the words of the open classes. The most common type of error falls into the category of adj- $n$. That is to say, Chinese learners tend to misuse an adjective as a noun. In other words, the adjective poses the greatest problem for Chinese learners, not the noun or verb as we thought it to be.

Thirdly, the acquisition of the word class has long been overlooked in English teaching and learning. Both teachers and learners haven't paid enough attention to it. Therefore, we should reassess the problems that word classes present Chinese learners with, and give special attention to it.

Last but not the least, possible measures can be taken to help learners acquire the word class. Due to the limited space, we'll focus on improvements in teaching material. For example, all the inflected forms of the same word family can be listed under the main entry of the new words in the textbooks. This will not only help learners learn the new word, but also enlarge their vocabulary. In addition, more exercises in the word class can be added in the textbooks. Finally, as an important aid to language learning, the dictionary should cater for the user's needs. As the Chinese-English dictionary is especially made for active use, the dictionary should provide the equivalents with the word class labels, especially when the head word has more than one word class. This will reduce the errors in the word class.

\section{REFERENCES}

[1] Corder, S. P. 1981. Error analysis and interlanguage[M]. Oxford: Oxford University Press.

[2] Crystal, D. 2003. The Cambridge Encyclopedia of the English Language (2nd ed.) [M]. Cambridge: Cambridge University Press.

[3] Ellis, R. 2008. The Study of Second Language Acquisition $\left(2^{\text {nd }}\right.$ edition) [M]. Oxford: Oxford University Press.

[4] Gui, Shichun, Yang, Huizhong. 2002. Chinese Learner English Corpus. Shanghai: Shanghai Foreign Language Education Press.

[5] Gui, Shichun. 2005. An analysis of speech errors of Chinese learner[A]. In Yang Huizhong, Gui Shichun, Yang Dafu (eds.) $A n$ Analysis of Chinese Learner's Interlanguage based on CLEC CC] (pp.1-109). Shanghai: Shanghai Foreign Language Education Press.

[6] Kolln, M. J. \& Funk, R. W. 2008. Understanding English Gram$\operatorname{mar}$ (8th ed.) [M], Longman.

[7] Selinker, L. 1992. Rediscovering Interlanguag[M]. London \& New York: Longman.

[8] Selinker, L. \& Lakshmanan, U. 1992. Language transfer and fossilization: the multiple effects principle[A]. In Gass, S. M. \& Selinker, L. (eds.) Language Transfer in Language Learning [C]. Amsterdam/Philadelphia: John Benjamins, 197-216. http://dx.doi.org/10.1075/lald.5.13sel

[9] Tao Xiaoyue. A Corpus-based Typological Analysis of the Written Errors Committed by Chinese English Majors [D]. Yangzhou University, 2006. 
PAPER

An ERror Analysis of the Word Class: A CASE Study of Chinese College Students

\section{AUTHOR}

Lixin Xia is with Guangdong University of Foreign Studies, Guangzhou, China, 510420.

Acknowledgements ; The research is sponsored by the 2013 special fund for "A Study on the Multi-Dimensional Definition Model for the
Chinese-English Dictionaries for Chinese Learners" (No. 2013WYXM0037) granted by the Department of Education of Guangdong Province. It is also part of the research achievements of the project "A study on China English Based on the China English Corpus" (No. GD14XWW20) funded by Guangdong Planning Office of Philosophy and Social Science in 2014. Submitted 23 March 2015. Published as resubmitted by the author 11 May 2015 .

APPENDIX

TABLE I.

The First 100 Errors With The Greatest Frequency

\begin{tabular}{|c|c|c|c|c|c|c|c|c|c|c|c|}
\hline No & Fre & Word & No & Fre & Word & No & Fre & Word & No & Fre & Word \\
\hline 1 & 81 & economic & 26 & 10 & great & 51 & 7 & lost & 76 & 5 & Chinese \\
\hline 2 & 78 & increasing & 27 & 10 & important & 52 & 7 & means & 77 & 5 & basic \\
\hline 3 & 66 & social & 28 & 10 & recently & 53 & 7 & health & 78 & 5 & past \\
\hline 4 & 47 & success & 29 & 10 & limit & 54 & 7 & sale & 79 & 5 & simply \\
\hline 5 & 38 & haste & 30 & 10 & prepare & 55 & 7 & adventure & 80 & 5 & easily \\
\hline 6 & 37 & developing & 31 & 9 & quick & 56 & 7 & suit & 81 & 5 & hurry \\
\hline 7 & 34 & healthy & 32 & 9 & hungry & 57 & 6 & wrong & 82 & 5 & danger \\
\hline 8 & 31 & live & 33 & 9 & global & 58 & 6 & perfect & 83 & 5 & practice \\
\hline 9 & 22 & raining & 34 & 9 & pleasure & 59 & 6 & easy & 84 & 5 & loss \\
\hline 10 & 21 & studying & 35 & 9 & failure & 60 & 6 & possible & 85 & 5 & graduation \\
\hline 11 & 18 & good & 36 & 9 & develop & 61 & 6 & industrial & 86 & 5 & they \\
\hline 12 & 17 & using & 37 & 8 & serious & 62 & 6 & guilty & 87 & 5 & use \\
\hline 13 & 17 & medical & 38 & 8 & rapid & 63 & 6 & rich & 88 & 5 & comfort \\
\hline 14 & 16 & practise & 39 & 8 & careful & 64 & 6 & seriously & 89 & 5 & understand \\
\hline 15 & 15 & choice & 40 & 8 & active & 65 & 6 & badly & 90 & 5 & require \\
\hline 16 & 14 & society & 41 & 8 & really & 66 & 6 & firstly & 91 & 5 & Practise \\
\hline 17 & 14 & importance & 42 & 8 & obviously & 67 & 6 & service & 92 & 5 & improve \\
\hline 18 & 14 & product & 43 & 8 & economics & 68 & 6 & image & 93 & 5 & fail \\
\hline 19 & 13 & short & 44 & 8 & sick & 69 & 6 & crime & 94 & 4 & successful \\
\hline 20 & 13 & serve & 45 & 8 & shortage & 70 & 6 & produce & 95 & 4 & slow \\
\hline 21 & 12 & difficult & 46 & 8 & serves & 71 & 5 & Last & 96 & 4 & technical \\
\hline 22 & 12 & well & 47 & 8 & living & 72 & 5 & serving & 97 & 4 & stable \\
\hline 23 & 11 & mainly & 48 & 7 & patient & 73 & 5 & ill & 98 & 4 & wealth \\
\hline 24 & 11 & succeed & 49 & 7 & interesting & 74 & 5 & harmful & 99 & 4 & socialism \\
\hline 25 & 11 & mean & 50 & 7 & happy & 75 & 5 & different & 100 & 4 & teach \\
\hline
\end{tabular}

TABLE II.

THE ClASSIFICATION OF THE FIRST 100 ERRORS

\begin{tabular}{|c|c|c|c|c|c|c|c|c|c|c|c|}
\hline No & Word & Type & No & Word & Type & No & Word & Type & No & Word & Type \\
\hline 1 & Good & $a d j-a d v$ & 26 & global & adj-n & 51 & badly & $a d v-a d j$ & 76 & graduation & $n-v$ \\
\hline 2 & Great & $a d j-a d v$ & 27 & active & $a d j-n$ & 52 & simply & $a d v-a d j$ & 77 & limit & $v-a d j$ \\
\hline 3 & Quick & $a d j-a d v$ & 28 & patient & $a d j-n$ & 53 & easily & $a d v-a d j$ & 78 & suit & $v-a d j$ \\
\hline 4 & Serious & $a d j-a d v$ & 29 & interesting & adj-n & 54 & haste & $n$-adj & 79 & use & $v-a d j$ \\
\hline 5 & Rapid & $a d j-a d v$ & 30 & happy & adj-n & 55 & society & $n-a d j$ & 80 & comfort & $v-a d j$ \\
\hline 6 & Careful & $a d j-a d v$ & 31 & possible & adj-n & 56 & importance & $n-a d j$ & 81 & live & $v-n$ \\
\hline 7 & Wrong & $a d j-a d v$ & 32 & industrial & adj-n & 57 & pleasure & $n$-adj & 82 & practise & $v-n$ \\
\hline 8 & Perfect & $a d j-a d v$ & 33 & guilty & $a d j-n$ & 58 & sick & $n$-adj & 83 & serve & $v-n$ \\
\hline 9 & Easy & $a d j-a d v$ & 34 & serving & adj-n & 59 & shortage & $n-a d j$ & 84 & succeed & $v-n$ \\
\hline 10 & Last & $a d j-a d v$ & 35 & ill & adj-n & 60 & health & $n$-adj & 85 & prepare & $v-n$ \\
\hline 11 & successful & $a d j-a d v$ & 36 & harmful & $a d j-n$ & 61 & hurry & $n-a d j$ & 86 & develop & $v-n$ \\
\hline 12 & Slow & $a d j-a d v$ & 37 & different & adj-n & 62 & danger & $n-a d j$ & 87 & serves & $v-n$ \\
\hline 13 & economic & $a d j-n$ & 38 & Chinese & $a d j-n$ & 63 & wealth & $n-a d j$ & 88 & produce & $v-n$ \\
\hline 14 & increasing & adj-n & 39 & basic & adj-n & 64 & socialism & $n$-adj & 89 & understand & $v-n$ \\
\hline 15 & Social & adj-n & 40 & technical & adj-n & 65 & success & $n-v$ & 90 & require & $v-n$ \\
\hline 16 & developing & $a d j-n$ & 41 & lost & $a d j-v$ & 66 & choice & $n-v$ & 91 & Practise & $v-n$ \\
\hline 17 & Healthy & adj-n & 42 & rich & $a d j-v$ & 67 & product & $n-v$ & 92 & improve & $v-n$ \\
\hline 18 & Raining & adj-n & 43 & past & $a d j-v$ & 68 & failure & $n-v$ & 93 & fail & $v-n$ \\
\hline 19 & Studying & adj-n & 44 & stable & $a d j-v$ & 69 & sale & $n-v$ & 94 & teach & $v-n$ \\
\hline 20 & Using & $a d j-n$ & 45 & well & $a d v-a d j$ & 70 & adventure & $n-v$ & 95 & mean & $v-n$ \\
\hline 21 & Medical & adj-n & 46 & mainly & $a d v-a d j$ & 71 & service & $n-v$ & 96 & living & life \\
\hline 22 & Short & $a d j-n$ & 47 & recently & $a d v-a d j$ & 72 & image & $n-v$ & 97 & firstly & first \\
\hline 23 & Difficult & adj-n & 48 & really & $a d v-a d j$ & 73 & crime & $n-v$ & 98 & they & their \\
\hline 24 & important & $a d j-n$ & 49 & obviously & $a d v-a d j$ & 74 & practice & $n-v$ & 99 & means & meaning \\
\hline 25 & Hungry & $a d j-n$ & 50 & seriously & $a d v-a d j$ & 75 & loss & $n-v$ & 100 & economics & economy \\
\hline
\end{tabular}

